chest X-ray examinations. One result of this approach has been the discovery that the percentage of undiagnosed cases of tuberculosis is higher among older people. In Norway, the Ministry of Social Affairs has the power to enforce X-ray sereening of part of, or all, the population, as well as to test for tuberculosis, and to give B.C.G. vaccination. The radiography services in Italy are aimed at detecting not only tubereulosis but also other respiratory diseases, cardiovascular diseases and lung tumours. Compulsory B.C.G. vaccination is practised in some countries, such as Yugoslavia. Tuberculosis is notifiable in most European countries, but not in The Netherlands, Portugal or Romania.

Thero is a good deal of variation in the regulations regarding immunization against such infections as smallpox, diphtheria, tetanus, and whooping cough. Smallpox vaccination is compulsory in most European countries, and it is prescribed by the International Sanitary Regulations. It is required, for example, in Czechoslovakia, Hungary, Turkey, the U.S.S.R., and Yugoslavia, but it is not compulsory in the United Kingdom. In Yugoslavia immunization against diphtheria and tetanus is also obligatory.

Some communicable diseases are confined to particular areas. In Europe, for example, trachoma is endemic only in the Mediterranean countries. Spain carries out trachoma control through a network of clinics helped by the World Health Organization and the United Nations International Children's Emergency Fund; in Greece, treatment and control are carried out through a chain of anti-trachoma dispensaries. In Italy provincial anti-trachoma associations have been set up in co-operation with public and school dispensaries, specialized hospital services, and district health visitor services. Turkey is gaining control over the disease through an increase in the number of dispensaries. Yugoslavia has made a successful attack on its foci of trachoma: senior medical students have carried out surveys among people in affected areas, and suspects are called for examination by specialists. Typhus, formerly widespread in eastern Europe, is now under control, and in Romania success has been achieved through co-operation between Government, the sanitation and epidemiological services, and the public. Public instruction in control methods has boen given by trade unions, co-operative services and the Red Cross organizations.

An important development in the control of communic. able disease has been the recognition of the part that veterinary science can play against zoonoses. In Italy, for example, there is a Veterinary Division within the Ministry of Health, which deals with such diseases as brucollosis, canine rabies and glanders. In Hungary, the sanepids (sanitary and epidemiological stations) have established programmes for brucollosis control in agricultural undertakings, helminthiasis control among school children, and ancylostomiasis control among miners. III Spain close co-operation is maintained betwoen the health authorities and the veterinary services in the control of brucellosis, tuberculosis transmitted by animals, and other zoonoses. Laboratory facilities, an essential element in the control of communicable diseases, are provided by the local sanepids in most eastern European countries, at the health offices in the Federal Republic of Germany and at the universities and hospitals in Austria. In England and Wales there is a national network of laboratories, operated on behalf of the Ministry of Health.

In Yugoslavia, the institutes of hygiene undertake special research projects, as well as routine examinations of public health specimens. This arrangement has been particularly helpful in special field campaigns against endemic syphilis and trachoma.

Other preventive services described in the monograph include food and drug control, matornal and child health, school health, occupational health, mental health and alcoholism, care of the aged, dental care, and health education.

\title{
ANTARCTIC AERONOMY AND ICE SHEETS
}

$\mathrm{D}$ URING the past ten years the amount of scientific data available from Antaretica has inereased by an order of magnitude. The position has at last been reached when it is stimulating and useful to summarize knowledge in many disciplines in the form of maps. The United States, the U.S.S.R. and the United Kingdom all have projects in hand to publish scientific atlases of Antarctic Research.

The Antarctic Map Folio Series is being published by the American Geographical Society under a contract with the National Science Foundation. The price is most reasonable and indicatos that considerable and welljustified financial support has been given by the National Science Foundation. The form of publication and the contents have been based on replies to lengthy question. naires sent to many interested scientists. The series will consist of about twenty folios, each devoted to one subject or scientific discipline. Each folio consists of a series of maps or diagrams printed on one side of sheets usually $17 \times 22$ in. and several pages of text of $17 \times 11$ in.; some plates are also of this size. Each folio series is contained in a light cardboard folder. Four colours are used in the production of maps.

The first folio* deals with aeronomy and has been produced by members of the AVCO Corporation, Wilmington, Massachusetts. A brief text explains the purpose of the observations and the method of compilation. It also

* American Geographieal Society. Antarctic Map Folio Series. Folio 1: teronomical Maps for the Antarctic. By R. Penndorf, T. M. Noel, G. F. llourke, and M. A. Shea. Pp. $6+9$ plates. (New York: American Geographical Society, 1964.) 3 dollars. includes brief outlines and maps of some data relevint to conjugate points and to the southern auroral zone. The definition of magnetic $B$ and magnotic $L$ values which is given is somewhat involved for the layman. The plates all show ionospheric conditions for 1957 or 1958, the period of maximum sunspot activity. The maps on at scale of about 1 : 100 million show the following parameters: $f_{0} E$ and $f_{0} F_{1}$ at 0000 and 1200 U.T.; $f_{0} F_{2}$ at $3 \mathrm{~h}$ (U.T.) intervals for winter, equinoctial and summer conditions, the percentage of time that $f_{0} E_{s}>5 \mathrm{Mc} / \mathrm{s}$, and magnetic $B$ and $L$ values at $0,100,200,500$, and $1,000 \mathrm{~km}$. The folio should be useful for general reference purposes for scientists in contact with ionospherie problems, but a non-specialist seeking a general appreciation of this work would learn more from a general review article.

The second folio $\dagger$ on the physical characteristics of the Antarctic ice sheet has been compiled in university and other institutes. It deals with several topics of general geographical interest. The Antarctic maps at $1: 13.6$ million are at a scale suitable to the detailed knowledge of many regions. Use of four-colour printing brings out general distributions clearly. Whero both colour shading and data figures are shown, as for net annual accumula. tion of snow and for mean annual temperatures, the effect is good, as one can see cloarly the actual measuroments and the degree of interpolation. However, the surface elevation and ice thickness maps show neither profile

$\dagger$ Folio 2: Physical Characteristics of the Antarctic Ice Sheet. By C. $\mathbf{R}$. Bentley, R. L. Cameron, C. Bull, K. Kojima and A. J. Gow. Pp. $10+1$ plates. (New York: American Geographical Society, 1964.) it dollars. 
lines nor points of observation, since the former are shown on a separate map. In theory one superimposes the maps on a light table as necessary -in practice a light table is not always available, and even if it is, the maps differ in placing in relation to the sheet edges, so that careful positioning is needed.

The maps give a reasonably full cover of material available in late 1963, but there are some omissions. Treatment of the Antaretic Peninsula by different compilers is inconsistent, since it is not always considered as part of the main ice sheet. Glaciological data frorn this region are both very variable and somewhat sparse, but ample information which is available on surface elevations has not been included. The text also states that meteorological observations have been obtained for one year or longer at twenty-one stations on the Antarctic Peninsula or off-lying islands, but the relevant map shows mean annual temperatures for only twelve of these stations. Reliable data for some of the missing stations are available from references given in the useful list of data sources which accompanies the text.

Another obvious omission is that the ice-thickness map does not show data from the French traverse of 1957-58 although the relevant reference is included with the text.
Studies of borehole data on temperatures, densities, crystal size and orientation, borehole closure and of stratigraphic profiles are shown diagrammatically on three data sheets. The introductory text is clear, and there is an excellent table setting out various over-snow traverses on the main continent, although the Antarctic Peninsula is again omitted.

For 7 dollars (3 dollars for Folio 1 and 4 dollars for Folio 2), the material supplied is good value and will provide a suitable reference source. Being in separate sheets, the maps can be revised and re-issued as necessary, and even in less than two years since they went to press, and under six months since their arrival in the United Kingdom, substantial additions to many of the maps could already be made. The intention in the United Kingdom and the U.S.S.R. to publish bound atlases at th definite time, rather than loose-sheet folios, has much to recommend it for convenience of librarians and general users. The maps are perhaps more important in supplying background information in fields related to a specialist's own studies, rather than to supply knowledge in his own field. Whatever the map, the specialist will almost always be aware of later data which are missing. G. DE Q. RobIN

\title{
OBSERVATIONS OF POLARIZED OH EMISSION
}

\author{
By Dr. S. WeINREB, Pro:- M. L. MEekS and J. C. CARTER \\ Lincoln Laboratory, Massachusetts Institute of Technology, Lexington, Massachusetts
}

AND

Prof. A. H. BARRetT and A. E. E. ROgerS

Research Laboratory of Electronics, Massachusetts Institute of Technology, Cambridge, Massachusetts

$I^{\mathrm{N}}$ N a recent article Weaver, Williams, Dieter and Lum $^{1}$ reported strong microwave emission lines in the $H$ II regions $W 3, W 49, W 51, W 75, N G C 6334$ and Orion $A$ at a frequency of approximately $1,665 \mathrm{Mc} / \mathrm{s}$. In some cases the lines exhibited complex spectral structure, and in all cases the emission at $1,667 \mathrm{Mc} / \mathrm{s}$ bore little resemblance in intensity and/or structure to the $1,665 \mathrm{Mc} / \mathrm{s}$ emission. In particular, the emission in the region of $W 3$ was approximately $30^{\circ} \mathrm{K}$ at $1,665 \mathrm{Mc} / \mathrm{s}$, while no emission was detected at $1,667 \mathrm{Mc} / \mathrm{s}$. Weaver et al. concluded. that the observations could not be entirely attributed to $\mathrm{OH}$ and postulated the existence of an unidentified. microwave line which they called "mysterium".

In this article we wish to report observations of emission lines near the source $W 3$ which reveal that: $(a)$ emission is present not only at $1,665 \mathrm{Mc} / \mathrm{s}$ but also at $1,667 \mathrm{Mc} / \mathrm{s}$ and $1,720 \mathrm{Mc} / \mathrm{s}$ with frequency spacings as predicted from the OH molecular spectrum ${ }^{2}$; (b) some of the emission at $1,665 \mathrm{Mc} / \mathrm{s}$ is linearly polarized by as much as 37 per cent; (c) the position of the maximum $1,665 \mathrm{Mc} / \mathrm{s}$ emission is displaced from $W 3$ by approximately $14 \mathrm{~min}$ of arc; (d) emission features as narrow as 1-1.5 kc/s have been observed. As yet we have not observed other regions. In our opinion, "mysterium" is anomalously excited $\mathrm{OH}$.

The observations were conducted using the 120 -ft. parabolic antenna of the Haystack Research Facility ${ }^{3}$ of Lincoln Laboratory, Massachusetts Institute of Technology, and a spectral-line autocorrelation radiometer. The radiometer is similar to that used in the initial discovery of the $\mathrm{OH}$ lines ${ }^{4}$; however, the present radiometer is an entirely new system with several improvements. A room-temperature parametric amplifier is incorporated in the radiometer, and a digital correlator allows the examination of the spectrum in band-widths which can be selected from $40 \mathrm{kc} / \mathrm{s}$ to $4 \mathrm{Mc} / \mathrm{s}$. The frequeney resolution is $1 / 40$ of the band-width. A Univac 490 computer is coupled directly to the radiometer output and produces the frequency spectrum immediately after the end of each pre-set integration time. The antenna beam-width is $23 \mathrm{~min}$ of arc and the overall system temperature is approximately $200^{\circ} \mathrm{K}$. The measured continuum antenna temperatures were approximately $240^{\circ} \mathrm{K}$ on Cassiopeia $A$ and approximately $12^{\circ} \mathrm{K}$ on $W 3$.

Typical emission spectra at 1,665, 1,667 and $1,720 \mathrm{Mc} / \mathrm{s}$ are shown in Fig. 1 and the results of our observations are summarized in Table 1. Because of our ability to examine the spectra with a frequency resolution of $1 \mathrm{kc} / \mathrm{s}$, more lines are reported in Table 1 than reported by Weaver et al. Most of our observations were also made at the position of maximum $1,665 \mathrm{Mc} / \mathrm{s}$ emission, $\alpha=2 \mathrm{~h} \mathrm{23m} \mathrm{29s}, \delta=+61^{\circ} 38 \cdot 1^{\prime}(1950 \cdot 0)$, slightly displaced from $W 3$. The region of strong emission at $1,665 \mathrm{Mc} / \mathrm{s}$

Table 1. Summary of Principal OH Spectral Featukes

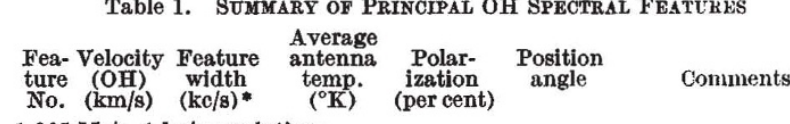
$1,665 \mathrm{Mc} / \mathrm{s}, 1 \mathrm{kc} / \mathrm{s}$ resolution:

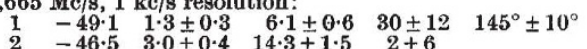

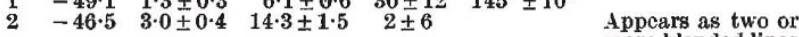

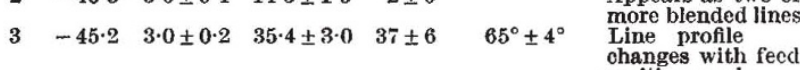

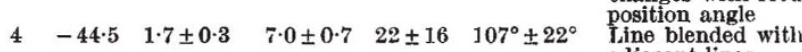

$\begin{array}{rrrrrr}5 & -43.7 & 1.6 \pm 0.2 & 14.8 \pm 1.5 & 22 \pm 10 & 140^{\circ} \pm 16^{\circ}\end{array}$ adjacent lines

$\begin{array}{llll}-43 \cdot 1 & 1 \cdot 2 \pm 0 \cdot 4 & 3 \cdot 1 \pm 0 \cdot 3 & 10 \pm 10\end{array}$

$1,667 \mathrm{Mc} / \mathrm{s}, 1 \mathrm{kc} / \mathrm{s}$ resolution:

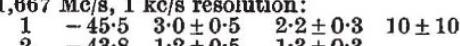

$\begin{array}{llll}2 & -43.8 & 1 \cdot 2 \pm 0.5 & 1.3 \pm 0.3 \\ 3 & -43.0 & 1.6 \pm 0.5 & 1 \cdot 7 \pm 0.3\end{array}$

$1,720 \mathrm{Mc} / \mathrm{s}, 3 \mathrm{ke} / \mathrm{s}$ resolution:

$\sim-44 \quad 0 \cdot 85 \pm 0 \cdot 3$

Spectrum not resolved due to poor signal-to-noise ratio

* Feature widths given have instrumental width removed. 